\title{
Civic Tech and Public Policy Decision Making
}

\author{
Carolyn J. Lukensmeyer, National Institute for Civil Discourse
}

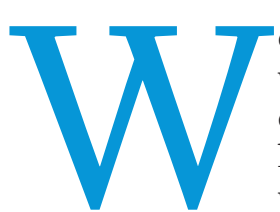

e live in a nation-and a world-facing very significant challenges, from climate change to the migration of people, to large-scale economic crises. Yet in recent years, the United States in particular has demonstrated near paralysis on such pressing issues. The extreme polarization of our politics, and the consequent disruption of governance, has rendered us mostly incapable of identifying viable solutions and moving them forward.

Technology-enabled, large-scale citizen engagement has enormous potential to help advance critical public policy issues. Unfortunately, however, the emerging civic tech field focuses the great majority of its intellectual and financial resources on citizen engagement aimed at community action, peer-to-peer information sharing, and data access and transparency efforts. This article makes the case that equal attention should be paid to civic tech applications that can take on our most pressing national policy issues. Further, it posits that large-scale citizen deliberation led by nongovernmental organizations (NGOs) will ultimately be limited by a lack of resources and scale, and that an investment in these processes by public institutions-via shifts in legal and institutional structures-is necessary.

\section{THE WANING OF OUR COLLECTIVE VOICE}

At the root of our nation's public policy paralysis is the fact that collective citizen voice is no longer a primary force driving the direction of the country on pressing issues. While such citizen voice historically exerted its influence through elections, significant structural shifts have upended that tradition. These shifts include excessive amounts of money distorting the electoral process; highly politicized redistricting practices; the alarming increase in fake news; and the fact that large swaths of the public do not vote: about $42 \%$ did not vote in the 2016 presidential elections (Regan 2016); 60\% do not vote in mid-term elections and even more choose not to vote in primaries and local elections (FairVote 2016). The result of these factors combined is that elections can routinely be hijacked by extreme ideologies in both parties as well as by monied interests. It has taken decades, but our country has come to a place where elections no longer reflect the collective public will and therefore are not a force driving common good resolutions to significant policy questions.

It will likely take further decades to resolve these structural issues and undo their damage. But in the meanwhile, alternative ways to bring collective citizen voice to the table will be essential. We must be able to engage people on a range of issues, with greater frequency, at larger scale, and with broader leadership commitment to pursuing the outcomes.

Fortunately, such engagement processes already exist. Practitioners of deliberative democracy have repeatedly shown their viability and power, and researchers in the field have evaluated their efficacy and impact. ${ }^{1}$ In short, it has been thoroughly demonstrated that when Americans are supported to participate in substantive dialogue and problem solving on challenging issues, they are able and willing to compromise and find workable solutions. More broadly utilized, the people's ability to do this would go a long way towards breaking up our gridlock and ensuring progress on pressing issues.

And indeed, citizen participation is being more broadly used in some contexts. The increasing popularity of participatory budgeting in the United States is one notable example. And, as explicated by other contributors to this symposium, we are seeing experimentation with this and other new engagement mechanisms; with efforts to reform participatory policy and practice; and with work to build capacity for participation at the local government and community levels. A key force behind many of these efforts is innovation in Information and Communications Technology (ICT), which is leading to a burgeoning "civic tech" industry.

While this new industry is incredibly exciting-especially to those of us who have practiced in the deliberative democracy field for decades-it is also important to note that not all facets of it are advancing equally. In a 2013 report (Patel, Sotsky, Gourley, and Houghton 2013), the Knight Foundation identified two primary landscapes in civic tech: organizations working towards "community action" and organizations working towards "open government." Community action efforts encompass activities such as organizing, crowdsourcing, neighborhood forums and peer-to-peer sharing. In the open government sphere, Knight defined six "clusters" of work: data access and transparency; data utility; public decision making; resident feedback; visualization and mapping; and voting.

While the field of civic tech is growing rapidly (at an annual rate of $23 \%$ from 2008-2012), Knight found marked differences in the growth rates between the two landscapes, and among the different clusters within each. For example, of the $\$ 431$ million that was invested in 102 civic tech organizations from January, 2011 to May, 2013, 82\% went to community action efforts. Within that category, a full two-thirds of the investments were aimed at peer-to-peer sharing. 
Of the $18 \%$ of total investments focused on open government work, nearly half went to data access and transparency efforts. Notably, public decision-making work, defined as "encourage [ing] resident participation in large-scale deliberative democracy and community planning efforts," received the lowest amount of funding, at less than 1\% (Patel et al. 2013).

In other words, as the field of civic tech moves rapidly forward (one study estimated total spending at $\$ 6.4$ billion in 2015) (Howard 2015), it seems clear that not all types are enjoying the surge in investment. In particular, civic tech aimed at decision making on public-policy issues-which serves to strengthen representative democracy and is the work with the greatest potential to help move the nation forward on deeply entrenched concerns-is the "low man on the totem pole."

In some ways, this should not be surprising. At a smaller and more local scale, improving the daily work of government and building more direct connections to constituents is readily achievable, especially with the application of ICTs. In many places, real changes in the community-from crime reduction to quicker snow removal-are happening and the quality of people's daily lives is improving. So there is strong appeal to pragmatic work like this.

And yet, inarguably, there is also critical work to be done to tackle the larger problems we experience in our communities and as a nation. Further, because online technologies and platforms enable unprecedented reach and scale, many believe these methods are naturally well-suited to largescale or national-level problem solving. And indeed, in the last decade, a few excellent examples have emerged, such as
The second characteristic is a radically populist embrace of the Web 2.o ethos that content is created and curated by the community of users with minimal investment in curation and organization...that informed, rational, and open-minded discussion will organically evolve without any further assistance.

When a universalist/populist conception of Civic Participation 2.o is implemented in a society with generally low levels of civic knowledge and few norms about the responsibilities of democratic participation, problems are predictable - and have been observed. The point is not that nothing useful has come from these participation ventures, but rather that the valuable submissions are needles that must be located in some very large hay-stacks. The burden on government officials to winnow submissions and acknowledge even dubious ones is matched by frustration on the part of participants, who perceive boilerplate responses and little responsive government action.

Based on more than 10 years of executive leadership in state and federal government, and more than 20 years as a leader in the field of citizen engagement, I wholeheartedly agree: breadth cannot, and should not, suffice for depth. Both are essential if engagement processes are to wield the influence we need them to wield. In short, the waning of our collective voice cannot be resolved by broader institution of methods that capture numbers but do not support the discovery of collective views that are fact-based, considered, and reach across significant differences. Further, achieving such depth requires-both my own and other experts' experience, as well as research in the field confirm-some degree of interpersonal interaction among participants.

\section{In short, the waning of our collective voice cannot be resolved by broader institution of methods that capture numbers but do not support the discovery of collective views that are fact-based, considered, and reach across significant differences.}

thegovlab.org, which is exploring and creating mechanisms to bring citizens into problem-solving efforts with government and other sectors.

However, upon closer inspection it is clear that many of the new platforms subscribe to a theory of engagement that treats breadth as a sufficient substitute for depth. Farina et al. (2014) aptly describe this problem, using the Obama Administration's Open Government work and Petitions.whitehouse. gov as a case in point:

Although there is no formal "model" of Civic Participation 2.0, the efforts of [the] Obama Administration to engage with citizens online seem to rely on two characteristics. The first is an assumption of universalism. Online, it is assumed, anyone regardless of age, citizenship, or other status - can make a suggestion...Moreover, some forms of participation - e.g., voting ideas up or down - may not require even [a] minimal commitment prior to voicing one's preferences.

\section{THE IMPORTANCE OF INTERPERSONAL INTERACTION}

In a world increasingly dominated by technology, it may seem outdated to assert the necessity of interpersonal interaction. And yet, such interaction is vital if citizen engagement is going to be effectively brought to bear on complicated and polarizing public issues in order to discover common ground solutions.

The reasons for this are straightforward. Elected leaders and decision makers are charged with executing the public's will. While one variety of public will can easily be generated by large numbers of people cutting, pasting, and instantly forwarding their opinions to their representatives, this "will" is essentially thin. It captures individuals' strongly held sentiments in the moment, but it does not provide an opportunity to wrestle with the complexities of an issue and consider alternate views. Without such wrestling, people tend to hold fast to their pre-existing views; they are neither energized nor supported to make the tough trade-offs that are embedded in policy decisions. 
As a result, the "cut and paste" manifestation of public will is less useful to decision makers on thorny policy issues that require discovery of a mutually acceptable path. Twenty-five years ago, Daniel Yankelovich articulated this very concern in Coming to Public Judgment (Yankelovich 1991). Unfortunately, as the power of the Internet makes aggregation of views increasingly expeditious, the essential shortcomings of this approach recede further and further from view.

To find the collective view of the public across strongly held differences, people must listen to each other with an open mind. In turn, they must feel and know that they have been heard; and they must have an opportunity to openly discuss their differences without fear of attack. Research confirms that such work is strongly dependent on interpersonal interaction, and therefore very unlikely to happen through linear online formats.

In 2010, TimeScience reported on a study by Kevin Rockmann of George Mason University and Gregory Northcraft at the University of Illinois in which 200 students were asked to problem solve on a project either by e-mail, videoconference, or in person. Among other findings, "those who met in person showed the most trust and most effective cooperation" (Luscombe 2010). Similarly, Frank Bryan's seminal study of more than 1,500 town meetings in Vermont over three decades demonstrated that when trying to build community and a movement of committed people, one of the elements that promoted that work most effectively was the experience of being face-to-face (Bryan 2003). In a 2014 exploration of online participation and deliberation mechanisms, Farina, Epstein, Heidt, and Newhart of the Cornell eRulemaking Initiative drew the same conclusion. "Whereas there is a growing body of evidence around the practice of democratic deliberation in physical, face-to-face settings, there is more skepticism about, and limited experience with, conducting political deliberation online," they argue. "One set of concerns focuses on the relative lack of social context in computer-mediated communication. Lack of social cues and the limited affordances for exchanging emotionally complex messages suggest that online discussion will be less effective than face-to-face deliberation" (Farina et al. 2014).

Without the capacity to support interpersonal interaction, it remains unclear whether new online citizen engagement methodologies can discover common ground among stronglyheld and divergent views on an issue. Developing large-scale methods that have this capacity therefore remains a critical frontier in the practice of deliberative democracy. Here I will explore three approaches to this challenge: first, using technology to scale-up face-to-face interaction; second, using face-to-face deliberation features to build the capacity of traditional technology-based methodologies; and third, using these distinct methods in an integrated engagement strategy that maximizes the advantages of each.

\section{USING TECHNOLOGY TO SCALE-UP FACE-TO-FACE} DIALOGUE

While achieving interpersonal interaction at scale remains a frontier, efforts have long been underway to unlock this puzzle, and progress has been made. In 1995, the national nonprofit AmericaSpeaks developed a citizen engagement methodology called the "21st Century Town Meeting" which supported thousands of representative citizens in deliberating together about critical issues using small, face-to-face groups, instant distillation of collective views, and large-group voting. The results of the citizens' work was strategically linked to live decision-making processes.

To achieve this, the 21st Century Town Meeting was the first in the field to bring technology to bear on the participatory process. Cutting edge at the time was the incorporation of hand-held polling keypads, networked laptop computers, and satellite and web-links to bring together geographically separated deliberation locations.

Since its inception, AmericaSpeaks, and its international arm Global Voices, have used the 21st Century Town Meeting in more than 200 projects in the United States and around the world, directly engaging more than 200,00o people. The model has also been replicated by other engagement organizations in Europe, Latin America, and Asia. The work repeatedly demonstrates that people can and will find common ground despite deep differences of opinion; that average citizens can handle complex content and make good decisions; and that large-scale public deliberations can transform "stuck" governance processes, with leaders indeed acting on what the public has to say.

Most recently, in the United States, the method was used to engage large numbers of citizens in helping to set policy and budget agendas, first for incoming Mayor Bill de Blasio in New York City and then for incoming Mayor Muriel Bowser in Washington, DC. Over the last few years, the nonprofit group Public Engagement Associates has also used the method to help 200 Washington, DC residents and stakeholders develop key priorities for the city's Office for Asian Pacific Islander Affairs; and to enable 400 Ohio State University alumni, faculty, staff, and community leaders to develop solutions on food security issues in Columbus and across the state. The National Institute for Civil Discourse is working with advocates and lawmakers to use the model to create large-scale dialogues about police-community relationships in Cleveland and Chicago.

To accomplish the goal of bringing citizen voices to bear on public decision making and governance, the 21st Century Town Meeting model follows these critical steps:

- It brings together the appropriate public decision makers and managers to prepare the decision options and corresponding educational material and to ensure their commitment to listening and utilizing the information and public voice that emerges from the discussions.

- It develops collaborative partnerships with large numbers of community organizations from all sectors that can conduct the extensive outreach needed to engage every subgroup of the population impacted by the issues under discussion, and holds government accountable for carrying out its commitments.

- It works directly with media outlets to ensure the entire community is aware of how to participate and can follow how the recommendations are implemented. 
Because the key decision makers are involved from the beginning and have made a commitment to taking the public's input seriously, these efforts have a real impact on policy and planning decisions and/or resource allocation. In just a few examples, the priorities and specifications for rebuilding lower Manhattan after September 11 and the city of New Orleans after the devastation of Hurricane Katrina, were directly shaped and improved by citizens' views; hundreds of millions of dollars were reallocated to align with citizens' priorities in Washington, DC. In another example with particular resonance following the recent presidential election, in the summer of 2010, in 57 cities across the country, 3,500 Americans from every walk of life, including Tea-Partiers, Move-On members, as well as average, middle-of-the-road citizens, came together and developed mutually-agreeable strategies for reducing the nation's deficit by $\$ 1.2$ trillion by $2025 .^{2}$ and communities, with small groups of participants watching a live webcast to monitor the progress of multiple groups' developing views while discussing and voting on the issue. "Virtual Summits" substituted the house party with a facilitated teleconference discussion linked to a centralized forum.

Both of these adaptations extended the scale and geographic reach of an in-person deliberative process, but they still required a not insignificant amount of organization, infrastructure and resources. And, while innovative at the time, in the context of today's mobile-tech-enabled participation options, the additional reach that was achieved by the networked house parties and virtual summits was not sufficient. In short, the work did not successfully "crack the code" for achieving even greater reach and scale while also supporting authentic face-to-face interaction that could build

\section{Because the key decision makers are involved from the beginning and have made a commitment to taking the public's input seriously, these efforts have a real impact on policy and planning decisions and/or resource allocation.}

Another important outcome of this work is that it helps create the infrastructure communities need to continue holding meaningful dialogues going forward. Such infrastructure includes legislative mandates for participation; the development of safe, accessible physical spaces that can accommodate large numbers; the capacity for facilitation; and local media accustomed to covering the work and its outcomes. Among numerous examples, in Northeast Ohio, the 18-month-long Voices \& Choices initiative-which directly engaged more than 21,00o people across 16 counties in setting an action agenda to revitalize their region's ailing economy-left in its wake regional planning groups and foundations that are still using the deliberative processes to understand and act on citizen priorities. ${ }^{3}$

\section{Early Adaptations Sought Even Greater Scale}

Although the 21st Century Town Meeting's primary advantage for many years was a unique capacity for scale, the method faced some challenges, such as relatively high production costs; labor-intensiveness for organizers; and time-intensiveness and access for participants. As a result, AmericaSpeaks began to experiment with ways to incorporate virtual participation without compromising the underlying commitment to interpersonal interaction and deliberation. The organization theorized that as long as virtual participants were fully engaged in the deliberative process-as opposed to simply monitoring it and tossing in an occasional comment-their ability to directly impact decision making would remain in tact.

In 2002 and 2003 AmericaSpeaks developed two adaptations to the 21st Century Town Meeting model that enabled substantive and interactive participation without physical presence at an in-person forum. "Networked House Parties" moved the deliberative process into homes, neighborhoods consensus across divergent viewpoints. It demonstrated that NGO-led deliberation is ultimately limited in scale by a lack of resources and ready access to broad swaths of the American public.

\section{A New Method: Text, Talk, Act}

In 2013, a group of deliberative democracy practitioners led by the National Institute for Civil Discourse (NICD) created a new engagement method aimed at increasing scale while retaining authentic face-to-face interaction. Text, Talk, Act was developed to bring young people into a national engagement process on mental health (described in more detail below). The method is a text message-enabled conversation that can be used by small groups of people, face to face, at a time and place of their choosing. It provides a safe space for honest, peer dialogue that, through the use of social media and a live comment stream, can also be part of a national effort.

To use Text, Talk, Act, small groups of three to five people text a number to receive a series of messages that guide them through an in-person conversation. They text responses to survey questions and forward their ideas for national, state, and local action. Participants are also encouraged to make on-the-spot action commitments for themselves, a friend in need, or their larger community. Discussion responses are posted to an interactive website and parallel conversations can be tracked through social media. Text, Talk, Act conversations are self-generating: although questions and prompts come via text message, individual groups determine how they want the conversation to proceed.

Since it was piloted in December of 2013, more than 70,00o people have used Text, Talk, Act to discuss and weigh-in on our nation's mental health challenges. It is the first tech-enabled citizen engagement process to connect 
texting with face-to-face group dialogue, and to link thousands of in-person discussions on the same subject.

\section{Additional Applications of the Method}

When NICD saw how effective the Text, Talk, Act platform was at engaging young people on mental health, work to adapt it to other engagement strategies, issues and population groups began immediately.

During the 2014-midterm elections, NICD launched "Text, Talk, Vote" as a pilot program in partnership with the University of New Hampshire and Tufts University. Functionally like Text, Talk, Act, this new iteration facilitated text messageenabled small group dialogue about voting and civic engagement: why it is important; how to overcome barriers to it; what issues matter most to participants; and where candidates stand on those issues. The text messages used to stimulate discussion on these topics included videos, social media interactions, and polling and discussion questions. Participants also received links to voter registration and for getting engaged in their communities.

In a small follow-up survey with students from the University of New Hampshire, more than half of participants stated that they came away from Text, Talk, Vote with new ideas or perspectives about their political involvement. One in five said that prior to Text, Talk, Vote, they were not planning to vote, but as a result of the conversation, they were committed to doing so.

Text, Talk, Vote was also successfully used in Akron, Ohio, in a Knight Foundation-funded effort to encourage civic engagement of millennials in the city's Mayoral race. Participant data will be linked to voter records to demonstrate Text, Talk, Vote's effectiveness in increasing turnout among young people.

The Text, Talk... platform was further adapted in March 2016, at the Ohio Civility Consortium: a town meeting in which multiple organizations came together to discuss the urgent crisis of rising incivility in American discourse. During this meeting, 232 people used "Text, Talk, Civility Matters" to explore the issues and consider a range of viewpoints and solutions. It was the first time the platform-originally designed with young people in mind-was used exclusively by adults, primarily academics and civic leaders. The response was very positive, suggesting that this engagement method can have broad appeal. It is now part of a large-scale NICD campaign offering citizens a variety of strategies for increasing civility in the current political context.

In a number of respects, Text, Talk, Act (and its adaptations to date) is similar to other interactive citizen engagement platforms. It provides an opportunity for spontaneous and "leaderless" engagement, is relatively low-cost for sponsoring organizations, and has the capacity to quickly reach broad audiences. Its significant value-add to the civic tech field is that it retains interpersonal interaction as a central component. As described here, such interaction creates the authenticity desired by decision makers as they seek to respond to the public will.

Given its promising start, further adaptations of Text, Talk, Act, will be an important lever for bringing greater scale to face-to-face citizen engagement on critical issues.
USING FACE-TO-FACE FEATURES TO BUILD CAPACITY IN ONLINE METHODS

The "flip-side" to using technology to scale-up face-to-face deliberation is to use face-to-face deliberation features to help technology-based methodologies dig into complex-and often conflict-laden-issues. There are a number of challenges in this endeavor, such as successfully moderating or facilitating large-scale online dialogues so they remain civil and productive; ensuring that dialogue is well-informed and fact-based so the results have utility for policy makers; and securing diverse participation that is representative of the population most affected by the issue under discussion.

One effort that made significant strides in this space is Regulation Room, the project of a multi-disciplinary team of students and faculty at Cornell University known as the Cornell eRulemaking Initiative (CeRI). CeRI worked to bring people into the complex process of federal rule and policy making in a substantive way. To accomplish this, the group tested a range of strategies for making complicated information more accessible in an online context. They used registration requirements to increase the likelihood of more substantive participation. And, they worked with different commenting and facilitation approaches to maximize knowledge building and the development of aligned viewpoints.

Beginning in 2009, CeRI ran deliberations related to six proposed federal rules, on consumer debt collection practices; home mortgage consumer protection; air travel accessibility; electronic on-board recorders for commercial motor vehicles; airline passenger rights; and texting while operating a motor vehicle. More than 48,ooo people visited Regulation Room to learn about these issues. Nearly 400 posted more than 2,400 comments. The final rules promulgated by the Consumer Financial Protection Bureau, the Department of Transportation, and The Federal Motor Carrier Safety Administration reflected comments developed on Regulation Room. ${ }^{4}$

Unfortunately, Regulation Room is concluding its activities. Funding for the work has dried up and they have been unable to persuade public agencies or foundations to support continued applications and research. The team will be putting the platform in an open source repository and will remain available for some period to consult on the technical side as well as on the operating practices.

During its seven years as an experimental platform, Regulation Room worked to deepen our understanding of deliberative behavior in an online context while also testing a set of new structures and strategies for improving the field's capacity in this area. It was seeking a methodology whose "participatory outputs are far more than the aggregation of individuals' pre-existing preferences" (Farina et al. 2014). The work created a mechanism for large-scale participation that is particularly well-suited for use in the public sector and on challenging issues of public policy. The shuttering of this successful and important effort is yet further evidence that the civic tech field is not prioritizing this kind of investment.

\section{INTEGRATING APPROACHES}

The third approach to achieving both breadth and depthto building large-scale engagement with the capacity for 
interpersonal interaction-is to bring distinct methods together in a single initiative, taking advantage of the strengths of each, while optimizing total participation and outcomes. This integrative strategy was recently employed with great success on the issue of mental health.

In the aftermath of the horrific tragedy at Sandy Hook, President Obama created an executive task force to develop actions that would respond to the dual challenges of gun violence and mental health. Among the recommendations endorsed by the President on January 16, 2013, was launching a National Conversation on Mental Health. Shortly afterwards, the administration reached out to the National Institute for Civil Discourse to develop the strategy for a community-based national discussion. NICD called on five other leading democracy organizations ${ }^{5}$ to bring each of their unique citizen engagement methods together, and take the conversation across the country. The federal government's Substance Abuse and Mental Health Services Administration (SAMHSA) was also a collaborating partner in the effort, developing and disseminating fact-based information that communities could use in their dialogues.

The resulting initiative-called Creating Community Solutions, or CCS-integrated three different pathways for engaging Americans in conversations that would lead to action on mental health: large-scale in-person dialogues in six lead cities; hundreds of smaller-scale conversations and activities in communities across the country; and Text, Talk, Act brought a new level of mutual accountability as well as the capacity for real collective impact. ${ }^{6}$

A number of factors led to CCS's success. In each community, the initiative created a temporary governance structure to guide the work and be held accountable for outcomes. While most large-scale citizen deliberation efforts rely on voluntary steering committees and/or the verbal commitment of local authorities, designation as a "lead city" for CCS required that organizations from all sectors (government, education, business, the nonprofit community) have a formal role and agree to be accountable for implementation of the recommendations for at least a year after the engagement.

Another innovation by CCS was the blending of largescale deliberative methodologies. Across the six lead cities, CCS utilized AmericaSpeaks' 21st Century Town Meeting, Everyday Democracy's community coalition model and The National Issues Forums Institute's community forums. Each of these organizations had, for decades, successfully built deliberative experience and capacity in different communities across the country. This preexisting infrastructure was key to achieving the rapid implementation that is often required of engagement initiatives yet difficult to achieve.

In the end, by integrating distinct engagement pathways and organizational methodologies, CCS engaged the largest number of citizens in face-to-face interaction across the broadest geography in the deliberative democracy field to date. It has successfully bridged breadth and depth.

\section{In a healthy democracy, citizens influence the development and implementation of public policy. Since such policy is primarily made and operationalized within government systems and agencies, the capacity and willingness of the public sector to embrace robust citizen engagement is key.}

(described earlier) to bring-in many thousands of young people. Because $75 \%$ of all mental health problems present before the age of 24 , finding ways to actively engage this group was especially critical to the initiative.

Since 2013, CCS has amassed substantial results. By integrating engagement methodologies, it has reached more than 81,500 people, has reduced stigma around mental illness in communities across the country, and has helped professionals and lay people alike build the skills needed to respond effectively to someone struggling with these challenges. With more than 105,800 sessions and 276,000 page views, the CCS website continues to be an important resource for communities that want to organize dialogues on mental health issues.

The integrated public engagement work of CCS has also succeeded in changing public systems across the countryfrom schools to law enforcement to health care-improving their capacity to meet the needs of people with mental health issues as well as their families and friends. Finally, CCS has built coalitions and working relationships that bridge the public and private sectors while also crossing many traditional lines of party and expertise. These distinct groups have

\section{THE PUBLIC SECTOR'S KEY ROLE}

Of the many partners involved in CCS, the participation of the public sector was among the most critical. In a healthy democracy, citizens influence the development and implementation of public policy. Since such policy is primarily made and operationalized within government systems and agencies, the capacity and willingness of the public sector to embrace robust citizen engagement is key. As described at the outset, the malfunctioning of our electoral systems makes this kind of participation all the more important.

Unfortunately, while the United States has long been a global leader in developing innovative technologies for incorporating public voice, other countries have adapted these processes and programs far more readily and are substantially ahead of us in making them intrinsic to governance. Countries such as Australia, Canada, Croatia, Estonia, Great Britain and Italy require engagement capacity in their public managers, train them to lead this work and allocate sufficient resources to routinely run engagement programs.

In the United States, by contrast, citizen engagement does not generally emanate from, or deeply connect with, the 
public sector. Rather, it is largely the province of nonprofits pushing from the outside. And, as the examples explored above demonstrate, this positioning will always be limited in its capacity to achieve real scale.

There are a number of structural and cultural reasons why the US public sector has not kept pace with other countries.7

First, public engagement activities are legislatively authorized (and therefore resourced) in only a small number of federal agencies. And, as Nabatchi and Leighninger point out in Public Participation for 21st Century Democracy, "most of the laws governing public participation are at least thirty years old" (2015). As a result, few public agencies have developed current and comprehensive practice in this arena. The Environmental Protection Agency, the US Fish and Wildlife Service, and the Department of Transportation are among those that have.

There are also a number of structural inhibitors to citizen engagement within government. One example is the Federal Advisory Committee Act (FACA). The procedural requirements and restrictions under FACA were well-intentioned when created, but had a chilling effect on governmental efforts to undertake public engagement. Despite efforts by the Administrative Conference of the US to address this concern, it remains a problem.

In addition, the engagement methods habitually employed (often, in fact, mandated) by government, such as public hearings, citizen advisory councils, and public comment periods, are frequently pro forma types of participation that lead to uninspiring results and then disinterest in the practice.

Further, many public managers are deeply embedded in a data-driven, "expert" culture, leaving them reluctant to trust ordinary people's ability to make substantive contributions, especially on technical and complex issues. This culture is also characterized by a degree of risk aversion among career civil servants, whose work can be complicated by regular shifts in political appointments and administrations. All of this can create a reluctance to open policy development and decision making to the "unpredictable whims" of the public.

Finally, the anti-government sentiment that has been a central feature of our nation's political debate for more than a decade demeans government workers and diminishes their willingness and ability to interact positively with the public, let alone broadly engage them.

While these are all powerful forces, we can, and must, counteract them. One of the most encouraging aspects of the civic tech work described in this article-the 21st Century Town Meeting, the Creating Community Solutions initiative and Regulation Room-is the explicit connection these efforts have all had to the public sector. Over the years, the 21st Century Town Meeting model has been employed more than 100 times by local, state, regional, federal and international government leaders or public agencies seeking to gather input on public policy priorities. Former Washington, DC Mayor Anthony Williams used the method for eight years to engage more than 13,00o people in establishing annual priorities for the city's budget.

The federal Substance Abuse and Mental Health Services Administration (SAMHSA) was a full partner in the Creating
Community Solutions initiative on mental health, supporting broad-based community participation in problem-solving. SAMHSA worked with local organizers, learned from what citizens recommended, and brought resources to the table while letting others take the lead on how to use them.

Finally, the work of the Cornell eRulemaking Initiative brought more than 48,000 people directly and effectively into one of the most complex and highly specialized processes in government.

Imagine the possibilities if more government agencies rallied behind citizen engagement in this way-if they routinely and effectively looked to the people to help develop and implement solutions to the issues they face. To do so, most agencies would need to make a number of changes: providing training and incentives; adopting new policies and procedures; and dedicating funds. And, the full array of new civic technologies must be brought to the table. This is where more active participation by leaders and investors in the civic tech field will be vital.

The civic tech field has made remarkable progress in ensuring that data are more universally accessible, in building more direct connections between local governments and their constituents, and in improving service delivery. Nabatchi and Leighninger provide an excellent review and analysis of many of these efforts (2015). And, as the previously-cited Knight Foundation report laid out, investors in the field have demonstrated strong support for this category of work.

However, given the urgency of our national concerns, equal attention must also be paid to advancing applications of civic tech that support people's engagement in largescale public policy-making. We must find new and better ways to bring interpersonal interaction into the picture, and embed this work in the tools the public sector uses to resolve the policy concerns facing us all. If the civic tech world ignores these challenges, citizen voices will remain on the sidelines and our many pressing national challenges will not be addressed.

\section{NOTES}

1. See, for example, Wilson, P. A., J. D. Padgett, and J. Wallace. 2007. New Orleans Community Congress II: Towards the Next Era of Participatory Democracy. Washington, DC: AmericaSpeaks; and Esterling, K., Archon Fung, and T. Lee. 2010. The Difference that Deliberation Makes: Evaluating the "Our Budget, Our Economy" Public Deliberation. Chicago: John D. and Catherine T. MacArthur Foundation.

2. More information about each of these examples can be found in Lukensmeyer, Carolyn. 2012. Bringing Citizen Voices to the Table. San Francisco, CA: Jossey Bass.

3. Ibid. Lukensmeyer. 2012.

4. Farina, Cynthia R. Cornell eRulemaking Iniative. Private communication with Wendy Jacobson, May 23, 2016.

5. AmericaSpeaks, https://en.wikipedia.org/wiki/AmericaSpeaks; Deliberative Democracy Consortium, www.deliberative-democracy.net; Everyday Democracy, www.everyday-democracy.org; The National Issues Forums Institute, www.nifi.org; and The National Coalition for Dialogue \& Deliberation, http://ncdd.org.

6. More information about CCS can be found at http://www. creatingcommunitysolutions.org/ or in Jacobson, Wendy. 2016. Out of the Shadows, Into the Light: How Community Conversations Can Transform our Nation's Approach to Mental Health. Tucson, AZ: National Institute for Civil Discourse.

7. These concepts are presented in more detail in: Lukensmeyer, Carolyn. 2012. Bringing Citizen Voices to the Table. San Francisco, CA: Jossey Bass; 
Lukensmeyer, Carolyn, Joe Goldman, and David Stern. 2011. Assessing Public Participation in an Open Government Era: A Review of Federal Agency Plans. IBM Center for the Business of Government Fostering Transparency and Democracy Series. Washington, DC: IBM Center for the Business of Government; and Lukensmeyer, Carolyn, and Lars Torres. 2006. Public Deliberation: A Manager's Guide to Citizen Engagement. IBM Center for the Business of Government Collaboration Series. Washington, DC: IBM Center for the Business of Government.

\section{REFEREN C ES}

Bryan, Frank M. 2003. The New England Town Meeting and How It Works. Chicago, IL: University of Chicago Press.

FairVote. 2016. "Voter Turnout in the United States." http://www.fairvote.org/ voter_turnout\#voter_turnout_101 (accessed May 23, 2016).

Farina, Cynthia R., Dmitry Epstein, Josiah Heidt, and Mary J. Newhart. 2014 "Designing an Online Civic Engagement Platform: Balancing "More" vs. "Better" Participation in Complex Public Policymaking." International Journal of E-Politics 5 (1): 16-39.
Howard, Alex. 2015. "Civic Tech in 2015: \$6.4 Billion to Connect Citizens to Services, and to One Another." TechRepublic. http://www.techrepublic.com/ article/civic-tech-in-2015-6-9-billion-to-connect-citizens-to-services-andto-one-another/ (accessed May 17, 2016).

Luscombe, Belinda. 2010. "Why E-Mail May Be Hurting Off-Line Relationships." Time (June 22, 2010) http://www.time.com/time/health/ article/o,8599,1998396,oo.html \#ixzz1kON7Ys1B, (accessed May 17, 2016)

Nabatchi, Tina and Matt Leighninger. 2015. Public Participation for 21st Century. Hoboken, NJ: Jossey Bass.

Patel, Mayur, Jon Sotsky, Sean Gourley, and Daniel Houghton. 2013. The Emergence of Civic Tech: Investments in a Growing Field. Miami, FL: Knight Foundation.

Regan, Michael D. 2016. "What Does Voter Turnout Tell Us About the 2016 Election?" PBS Newshour, November 2o. http://www.pbs.org/ newshour/updates/voter-turnout-2016-elections/ (accessed January 2, 2017).

Yankelovich, Daniel. 1991. Coming to Public Judgment: Making Democracy Work in a Complex World. Syracuse, NY: Syracuse University Press. 